\title{
A GLOBAL CONTINUOUS PLANKTON RECORDER PROGRAMME
}

Philip, C. Reid ${ }^{(1,2,3)}$, Ulrich Bathmann ${ }^{(4)}$, Sonia D. Batten ${ }^{(5)}$, Russell E. Brainard ${ }^{(6)}$, Peter H. Burkill ${ }^{(7,2)}$, Francois Carlotti $^{(8)}$, Sanae Chiba ${ }^{(9)}$, Alessandra Conversi ${ }^{(10,2)}$, Robert R. Dickson ${ }^{(11)}$, Harry Dooley ${ }^{(12)}$, Martin Edwards ${ }^{(13,2)}$, Juha Flinkman ${ }^{(14)}$, Mitsuo Fukuchi ${ }^{(15)}$, Joaquim Goes ${ }^{(16)}$, Gustavo Goni ${ }^{(17)}$, Charles H. Greene ${ }^{(18)}$, Jonathan A. Hare ${ }^{(19)}$, Graeme C. Hays ${ }^{(20)}$, Erica Head ${ }^{(21)}$, Raleigh R. Hood ${ }^{(22)}$, Graham Hosie $^{(23)}$, Brian P. V. Hunt ${ }^{(24)}$, Anthony W.G. John ${ }^{(25)}$, Tanya D. Jonas ${ }^{(26)}$, Jack W. Jossi ${ }^{(27)}$, Bengt Karlson $^{(28)}$, Kuh Kim ${ }^{(29)}$, Richard R. Kirby ${ }^{(30)}$, John Kitchener ${ }^{(31)}$, Donald Kobayashi ${ }^{(32)}$, Sami Lakkis ${ }^{(33)}$, Marcos Llope $^{(34,35)}$, Rubens M. Lopes ${ }^{(36)}$, Alison MacDiarmid ${ }^{(37)}$, Abigail McQuatters-Gollop ${ }^{(38)}$, Tom Malone ${ }^{(39)}$, Prabhu Matondkar ${ }^{(40)}$, Erik Muxagata ${ }^{(41)}$, Andrew Pershing ${ }^{(42)}$, Anthony J. Richardson ${ }^{(43,44)}$, Don Robertson ${ }^{(45)}$, Karen Robinson $^{(46)}$, Aida Sartimbul ${ }^{(47)}$, Nils C. Stenseth ${ }^{48)}$, Hiroya Sugisaki ${ }^{(49)}$, Darren Stevens ${ }^{(50)}$, Edward Vanden Berghe ${ }^{(51)}$,Hans Verheye ${ }^{(52)}$, Luigi Vezzulli ${ }^{(53)}$, Peter Ward ${ }^{(54)}$

(1) Sir Alister Hardy Foundation for Ocean Science (SAHFOS), The Laboratory, Citadel Hill, Plymouth PL1 2PB, UK. Email:pcre@sahfos.ac.uk

(2) Marine Institute, University of Plymouth, Drake Circus, Plymouth PL4 8AA, UK.

(3) Marine Biological Association, The Laboratory, Citadel Hill, Plymouth PL1 2PB, UK.

(4) Polar Biological Oceanography, Alfred-Wegener-Institute Polar and Marine Research, D-27515 Bremerhaven, Germany. Email: ulrich.bathmann@awide

(5) Sir Alister Hardy Foundation for Ocean Science, 4737 Vista View Crescent, Nanaimo, British Colombia V9V 1N8, Canada.Email:soba@sahfos.ac.uk

(6) NOAA Pacific Islands Fisheries Science Center/Coral Reef Ecosystem Division, 1125B Ala Moana Boulvard, Honolulu, Hawaii, 96814, USA. Email: rusty.brainard@noaa.gov

(7) Sir Alister Hardy Foundation for Ocean Science, The Laboratory, Citadel Hill, Plymouth PL1 2PB, UK. Email: phb@sahfos.ac.uk

(8) Laboratoire d'Océanographie Physique et Biogéochimique - Unité Mixte de Recherche 6535 - C.N.R.S., StationMarine d'Endoume, Université de la Méditerranée - Observatoire des Sciences de l'Univers (OSU) - Centre d'Océanologie de Marseille (COM), Rue de la Batterie des Lions, F- 13007 Marseille, France. Email: francois.carlotti@univmed.fr

(9) EBCRP, JAMSTEC, 3173-25 Showa-machi, Kanazawa-ku, Yokohama 236-0001, Japan. Email: chibas@jamstec.go.jp

(10) CNR - ISMAR - La Spezia, Forte Santa Teresa, Pozzuolo, 19032 Lerici (SP), Italy. Email:a.conversi@ismar.cnr.it

(11) Centre for Environment, Fisheries and Aquaculture Science (CEFAS), The Laboratory, Pakefield Road, Lowestoft, Suffolk NR33 OHT, UK. Email: r.r.dickson@cefas.co.uk

(12) Castanea, Andrews Park, The Woll, Ashkirk, Selkirk TD7 4NY, Scotland, UK. Email: hddooley@yahoo.co.uk

(13) Sir Alister Hardy Foundation for Ocean Science, The Laboratory, Citadel Hill, Plymouth PL1 2PB, UK. Email: maed@sahfos.ac.uk

(14) Marine Research Center, Finnish Environment Institute SYKE, Mechelininkatu 34a, P.O. Box 140, FI - 0025I Helsinki, Finland. Email: Juha.Flinkman@ymparisto.fi

(15) National Institute of Polar Research 9-10, Kaga 1-chome, Itabashi-ku, Tokyo 173-8515, Japan. Email: fukuchi@nipr.ac.jp

(16) Bigelow Laboratory for Ocean Sciences, P.O. Box 475, 180 McKown Point Road, West Boothbay Harbor, Maine 04575-0475, U.S.A. Email: goes@bigelow.org

(17) NOAA/AOML/PHOD, 4301 Rickenbacker Causeway, Miami, Florida, 33149, USA. Email: Gustavo.Goni@noaa.gov (18) Ocean Resources and Ecosystems Program, Department of Earth \& Atmospheric Sciences, 2130 Snee Hall, Cornell University, Ithaca, New York, 14853 USA. Email: chg2@cornell.edu

(19) NOAA NMFS Northeast Fisheries Science Centre, Narragansett Laboratory, 28 Tarzwell Road, Narragansett, Rhode Island 02882,USA. Email: jhare@mola.na.nmfs.gov

(20) Institute of Environmental Sustainability, Swansea University, Singleton Park, Swansea SA2 8PP, UK. Email:g.hays@swan.ac.uk

(21) Fisheries and Oceans Canada, Ecosystem Research Division, Bedford Institute of Oceanography, P.O. Box 1006, Dartmouth, Nova Scotia B2Y 4A2, Canada.Email: erica.head@dfo-mpo.gc.ca

(22) Horn Point Laboratory, University of Maryland Centre for Environmental Science, P.O. Box 775, Cambridge, Maryland,21613,USA.Email: rhood@hpl.umces.edu

(23) Australian Antarctic Division, 203 Channel Highway, Kingston, Tasmania, 7050, Australia. Email:Graham.Hosie@aad.gov.au

(24) Department of Earth and Ocean Sciences, The University of British Columbia, 6339 Stores Road, Vancouver, British Columbia V6T 1Z4, Canada.Email: bhunt@eos.ubc.ca 
(25) Sir Alister Hardy Foundation for Ocean Science, The Laboratory, Citadel Hill, Plymouth PL1 2PB, UK. Email:awgj@sahfos.ac.uk

(26) Sir Alister Hardy Foundation for Ocean Science, The Laboratory, Citadel Hill, Plymouth PL1 2PB, UK. Email:tio@sahfos.ac.uk

(27) NOAA NMFS Northeast Fisheries Science Center, Narragansett Laboratory, 28 Tarzwell Road, Narragansett, Rhode Island, 02882, USA. Email: Jack.Jossi@noaa.gov

(28) Swedish Meteorological and Hydrological Institute, Research \& Development, Oceanography, Sven Källfelts gata, 15, SE-426 71 Västra Frölunda, Sweden. Email: bengt.karlson@smhi.se

(29) Environmental Science and Engineering Department, Pohang University of Science and Technology, Hyoja-dong, Nam-gu, Pohang , Kyungsang-bukdo, 790-784, Republic of Korea. Email: kuhkim@gmail.com

(30) Royal Society University Fellow, University of Plymouth, UK, Marine Biological Association and Sir Alister Hardy Foundation for Ocean Science, The Laboratory, Citadel Hill, Plymouth PL1 2PB, UK. Email: richard.kirby@plymouth.ac.uk

(31) Australian Antarctic Division, 203 Channel Highway, Kingston, Tasmania, 7050, Australia. Email: john.kitchener@aad.gov.au

(32) Ecosystems \& Oceanography Division, Pacific Islands Fisheries Science Center, NOAA/NMFS, 2570 Dole Street, Honolulu, Hawaii, 96822, USA. Email: Donald.Kobayashi@noaa.gov

(33) Section of Oceanography, Lebanese University, Beirut, Lebanon. Email: slakkis@ul.edu.lb

(34) Instituto Español de Oceanografía (IEO), Centro Oceanográfico de Cádiz, Muelle de Levante (Puerto Pesquero), Apdo. 2609, 11006 Cádiz, Spain.

(35) Centre for Ecological and Evolutionary Synthesis (CEES), Department of Biology, University of Oslo, P.O. Box 1066, Blindern, N-0316 Oslo, Norway.Email: marcos.1lope@bio.uio.no

(36) Oceanographic Institute, University of São Paulo, Pr. Oceanografico 191, Sao Paulo, SP 05508-120, Brazil. Email: rubens@usp.br

(37) NIWA (National Institute of Water \& Atmospheric Research), 301 Evans Bay Parade, Private Bag 14-901, Wellington 6021, New Zealand. Email: a.macdiarmid@niwa.co.nz

(38) Sir Alister Hardy Foundation for Ocean Science, The Laboratory, Citadel Hill, Plymouth PL1 2PB, UK. Email: abiqua@sahfos.ac.uk

(39) Horn Point Laboratory, University of Maryland Center for Environmental Science, P.O. Box 775, Cambridge Maryland, 21613, USA. Email: malone@hpl.umces.edu

(40) National Institute of Oceanography (NIO), Dona Paula - 403 004, Goa, India. Email: sgpm@nio.org

(41) Universidade Federal do Rio Grande, Laboratório de Zooplâncton - Instituto de Oceanografia, Av. Itália Km, 8- Campus Carreiros - Caixa Postal 474, 96201-900 - Rio Grande- RS, Brazil. Email: e.muxagata@ gmail.com

(42) University of Maine, School of Marine Sciences, Gulf of Maine Research Institute, 350 Commercial Street Portland, Maine 04101,USA. Email: andrew.pershing@maine.edu

(43) Commonwealth Scientific and Industrial Research Organisation (CSIRO), Marine and Atmospheric Research,

P O. Box 120, Cleveland, Queensland 4163, Australia.Email: anthony.richardson@csiro.au

(44) University of Queensland, School of Mathematics and Physics, St. Lucia, Queensland 4072, Australia.

(45) NIWA, 301 Evans Bay Parade, Private Bag 14-901, Wellington 6021, New Zealand. Email: d.robertson@niwa.co.nz (46) NIWA, 10 Kyle Street, Riccarton, PO Box 8602, Christchurch, New Zealand. Email: k.robinson@niwa.co.nz

(47) Faculty of Fisheries and Marine Sciences, University of Brawijaya, Jalan Veteran, Malang 65145, Indonesia. Email: aidasartimbul@yahoo.com

(48) Centre for Ecological and Evolutionary Synthesis (CEES), Department of Biology, University of Oslo, P.O. Box 1066, Blindern, 0316, Oslo, Norway.Email: n.c.stenseth@bio.uio.no

(49) Tohoku National Fisheries Research Institute, 3-27-5 Shinhama-cho, Shiogama, Miyagi, 985-0001, Japan. Email:sugisaki@myg.affrc.go.jp

(50) Sir Alister Hardy Foundation for Ocean Science, The Laboratory, Citadel Hill, Plymouth PL1 2PB, UK. Email: dpst@sahfos.ac.uk

(51) Ocean Biogeographic Information System (OBIS), Institude of Marine and Coastal Sciences, Rutgers, The State University of New Jersey, 71 Dudley Road, New Brunswick, NJ 08901-8521 USA.

Email: evberghe@iobis.org

(52) Biological Oceanography, Marine \& Coastal Management, Department of Environmental Affairs and Tourism(DEAT), Private Bag X2, Rogge Bay 8012, Foretrust Building, 2nd Floor - Room A2-58, Martin Hammerschlag Way, Foreshore, Cape Town, South Africa.Email: hverheye@deat.gov.za or hans.verheye@gmail.com (53) Department of Biology, University of Genoa, Viale Benedetto XV, 516132 Genoa, Italy. Email:luigi.vezzulli@unige.it

(54) British Antarctic Survey, High Cross, Madingley Road, Cambridge CB3 0ET, UK. Email: pwar@nerc-bas.ac.uk 


\section{ABSTRACT}

Plankton are the main food source in the majority of marine ecosystems and have a crucial role in climate change through primary production and the export of carbon to the deep ocean. Understanding how ocean biology and biogeochemical cycles contribute and respond to climate and other global change is a major challenge of high significance for the future of mankind. Given their importance, it is a major concern that, with the exception of data collected by the Continuous Plankton Recorder (CPR) survey, our knowledge of plankton at ocean scales and over time is still rudimentary. Using ships of opportunity, the CPR survey has sampled the plankton for more than 75 years in the North Atlantic, aided more recently by sister surveys in Southern Ocean, North Pacific and Australasian waters. Monitoring plankton variability over large areas of oceanic and coastal water with the CPR is efficient and cost effective and is a powerful, proven tool for detecting and predicting oceanic impacts of both global and climate change. There is an urgent need to improve global coverage of plankton and provide data for modelling. To address this need we propose the development and implementation of an integrated and appropriately funded global CPR programme linked to SOOP/VOS (Ship of Opportunity Program/Volunteer Observing Ship. Our vision is to build regional surveys with common standards for sampling, analysis, data processing and sample storage that generate compatible and freely exchangeable data. It is envisaged that the resulting global network, of preferably instrumented CPR routes, would be closely associated with other traditional and new plankton sampling and analysing technologies, plus remote sensing and the Global Tracking Network (GTN). To develop this network it is proposed that SAHFOS (Sir Alister Hardy Foundation for Ocean Science) should have a central role as a 'Centre of Excellence' for coordination, training and quality control, as well as the production of indicators, habitat niche modelling and other global outreach products.

\section{INTRODUCTION}

We face major challenges in understanding how ocean biology responds to global change and equally important how life in the ocean and associated biogeochemical cycles contribute to global and especially climate change. Recent research suggests that both these challenges are considerable and of great significance for mankind. Understanding the synergistic impacts of global climate change on marine ecosystems requires observations on time scales of months to decades and at basin level spatial scales. Such 'climate data records, ${ }^{1}$ are common for physical variables such as temperature, but are rare for biological properties, especially in the ocean.
Plankton are a crucial component of the Earth's biosphere since they are the key food source for the majority of marine ecosystems and drive biogeochemical cycles with important feedbacks to climate. Phytoplankton account for $\sim 50 \%$ of combined marine and terrestrial global primary production, and form the base of most marine food webs. The herbivorous zooplankton graze on phytoplankton and serve to transfer energy from primary producers to fish, seabirds, and cetaceans. Most fish juveniles are planktivorous, and many species important to humans remain planktivorous throughout their life. Overall this means that the carrying capacity of ecosystems in terms of the biomass of fish resources and recruitment to stocks is highly dependent on variations in the abundance, timing and composition of plankton. The plankton also play a central role in the carbon cycle through the export of organic and inorganic carbon to the deep ocean, via what is known as the 'biological pump'. Without this process, concentrations of atmospheric $\mathrm{CO}_{2}$ would be much higher than they are now and the climate of the world (at present levels of solar radiation) would be considerably warmer. In addition to $\mathrm{CO}_{2}$ drawdown, phytoplankton play a key role in the production of oxygen and other climatologically relevant gases. New advances in molecular methods have allowed the study of bacterioplankton and many new microbial organisms and processes have been discovered with a potential for commercially important bioproducts. By integrating the signals of their living environment, plankton also act as sensitive indicators of global change, often showing change well before it is detected by physical or chemical observations [1]

Given their important roles in the biosphere, there is an urgent need to improve our ability to document changes in the abundance and distribution of planktonic organisms in both time and space. On a global scale, other than information from satellites, there are only limited biological observing programmes in place. Although some progress has been made recently in characterising functional groups of plankton from satellite data, in general they only provide information on chlorophyll pigments and there is incomplete coverage in many regions due to cloud cover. The only routinely deployed sampling system that provides detailed biological data on ocean basis scales is the Continuous Plankton Recorder (CPR). CPRs are towed on voluntary ships of opportunity (SOOP), making the programme highly cost effective compared to research vessels deployed over similar large areas of ocean. Initiated in the 1930s, this robust and well tried

1. A climate data record is "a time series of measurements of sufficient length, consistency and continuity to determine climate variability and change." http://www.ncdc.noaa.gov/sds/cdr/index.html 
methodology is a powerful, proven tool for detecting, understanding and predicting the impacts of global and climate change on the biosphere, as well as contributing to the understanding of feedbacks from ocean ecosystems to climate change.

Here we outline a proposal to develop and implement an integrated and appropriately funded global plankton observation programme using ships of opportunity. It is envisaged that the $\mathrm{CPR}$ will provide a network to connect with other non-CPR traditional and new plankton sampling and analysing technologies as part of a 'commonwealth' of regional integrated marine observing programmes. Wherever possible the CPRs should be towed on the same ships and routes as used for expendable bathythermograph (XBT), thermosalinograph (TSG), pCO2 and other ship of opportunity measuring programmes. The vision is to achieve a coordinated global CPR programme made up of regional surveys that utilise common international standards for sampling, analysis, data processing and sample storage, and that is closely associated with other SOOP and ocean monitoring initiatives.

\section{THE CPR PROGRAMME 1920 TO PRESENT}

Continuous Plankton Recorders (Figs. 1 and 2) are towed at speeds of up to 25 knots, sampling the near surface plankton at a depth of $\sim 7 \mathrm{~m}$ [2]. The plankton is filtered by a continuously moving band of $270 \mu \mathrm{m}$ mesh silk gauze. Water enters through a small aperture (1.27 $\mathrm{cm}$ square) at the front, which expands to a rectangular cross section (10cm wide) across which passes the silk band that filters the plankton (Fig. 2). The silk slowly moves across the filtering area at a rate that is proportional to the speed of the towing ship so that $5 \mathrm{~m}$ of silk is equivalent to $\sim 500$ nautical miles (nm) of tow. In effect the band of silk when unrolled is like a film roll of the changing plankton along the route of the towing ship. The silk is cut into sections equivalent to 10 nautical miles of tow $(5 \mathrm{~nm}$ in the Southern Ocean CPR survey, SO-CPR) for identification and counting of phytoplankton and zooplankton under a microscope.

After deployment of a prototype CPR in the Southern Ocean in the 1920s, a smaller machine suitable for use on merchant ships was built and trialled in the North Sea in 1931 [3]. Routine monthly tows were subsequently established, later to expand into the North Atlantic (Fig. 3). Since 1991, the monthly North Atlantic survey has been operated by the Sir Alister Hardy Foundation for Ocean Science (SAHFOS), an internationally funded non-profit organisation.

Deployment of CPR machines has proved to be an efficient and cost-effective way of monitoring plankton variability, at regular monthly intervals, over large areas of oceanic and coastal water. It is the only sampling system that can provide oceanic biological data that can be used to detect interannual and decadal trends at the scale of ocean basins. A key aspect of the success of the survey resides in the standardisation and the minimal changes that have been implemented since the 1930 s in the machine, methods of sampling, analysis and quality assurance procedures. Zooplankton analysis methods have changed little since prior to the Second

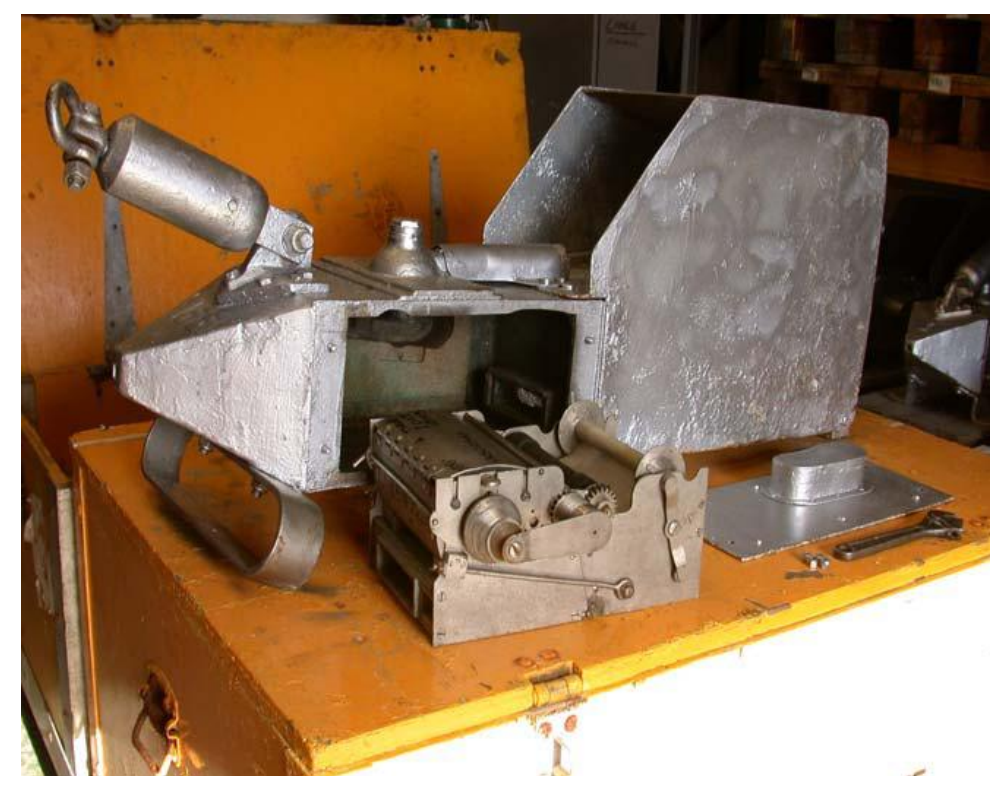

Figure 1. Photograph of a Continuous Plankton Recorder with the sampling cassette removed to show a silk spool and preservative storage tank. 
World War and phytoplankton identification and enumeration procedures have remained virtually constant since January 1958.

Tows have been made by CPRs in almost all the major ocean basins (Figs. 3 and 4). Surveys are currently operational in the North Atlantic, North Pacific, Southern Ocean and Tasman Sea with others in the planning stage. The Narragansett Laboratory of the National Oceanic and Atmospheric Administration (NOAA)/National Marine Fisheries Service (NMFS) in the USA has operated two CPR routes off the east coast of the USA since 1972 [4]. In the North Pacific a new survey was started by SAHFOS in 1997 and now operates two routes, one between Canada and Japan [5]. New routes were initiated by SAHFOS in the Barents
For many of these samples Phytoplankton Colour (a visual measure of chlorophyll) has also been determined.

In New Zealand, a programme operated by the National Institute of Water and Atmospheric Research (NIWA), in partnership with the New Zealand's Ministry of Fisheries (MFish), was started in 2008 and is towing CPRs half yearly between Wellington and Chatham Rise and on a route to Antarctica. A new Australasian CPR survey started in 2009 along the eastern coast of Australia [7]. The German programme in the SO is operated by AWI and covers the service and science route from South Africa to the Antarctic Neumayer Station (Greenwich meridian). Other pilot surveys have operated in the Caribbean, Gulf of Guinea, the

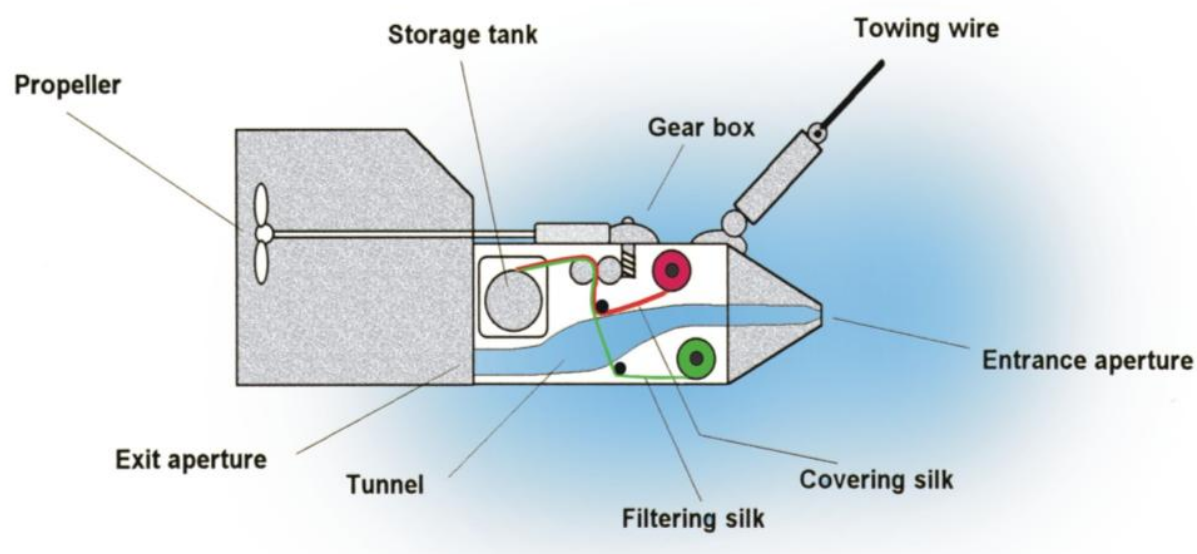

Figure 2. Schematic of the CPR showing water passing through the filtering silk (green). The gearing mechanism is powered by an impellor. A second band of silk (red spool) covers the filtering mesh to form a sandwich that holds on the plankton as it is wound into onto a spool in a storage tank containing formaldehyde fixative and preservative.

Sea in 2008 and the Norwegian Sea between northern Norway and Iceland in 2009. Sampling with the CPR between South Georgia and the Falkland Islands started in 2005 in partnership between the British Antarctic Survey (BAS) and SAHFOS. This survey expanded in subsequent years to a triangular route that includes the South Orkney Islands in the Scotia Sea. A sister Southern Ocean CPR (SO-CPR) survey, now adopted by the Scientific Committee on Antarctic Research (SCAR), that is coordinated by the Australian Antarctic Division (AAD), Department of Environment, Water, Heritage and the Arts, has been growing since 1991 [6]. This latter survey has conducted tows all around Antarctica. The resulting database from the SAHFOS, NOAA/NMFS and SO surveys of $>230,259,8,722$ and 25,791 analysed samples respectively, from more than 5 million miles of tow, has recorded $>600$ species/taxa.
Mediterranean and Baltic Seas, around the Seychelles in the Indian Ocean, in the Gulf of California and in the Great Lakes. In 2005 a successful 'proof-of-concept' tow was made around southern Africa. A proposal has recently been submitted in South Africa to The Benguela Current Commission (BCC) to develop this survey in the long-term using ships-of-opportunity between Durban on the South African east coast and Cabinda, Angola. Plans are in hand to tow between Honolulu and the Mariana Islands in 2010, in the Gulf of California and between the UK and the Falkland (Malvinas) Islands and a proposal is being developed within the Sustained Indian Ocean Biogeochemical and Ecological Research (SIBER) initiative to operate a route across the Indian Ocean. The National Institute of Oceanography, India has purchased a CPR and is investigating options for its routine deployment in the 
Arabian Sea. In Brazil, the Oceanographic Institute is developing plans and seeking a partnership to establish routes in Latin America and the Caribbean, with potential extensions to African and Asian countries such as Nigeria and Singapore. Finally, in September 2009, a CPR was towed between the UK and Brazil on the Dutch sailing ship Stad Amsterdam, as part of a voyage that is replicating the route of Darwin's Beagle.

\section{SOME KEY RESULTS}

Data from past and current CPR surveys has proved to have a wide variety of research applications and this unique time series is increasingly recognised as a 'barometer' against which climate change and pollution/eutrophication effects on marine ecosystems can be assessed. Survey products have been used: to describe and analyse the biogeography, seasonal cycles and year-to-year variability of plankton in relation to hydro-meteorological change, to provide information on harmful algal blooms, to monitor the spread of nonindigenous plankton species, to describe changes in marine biodiversity and trophic cascading and to model the response of plankton to global warming, including the development of habitat niche modelling. The data have also been used to interpret changes in fish stocks [8] and as environmental input to new approaches to fisheries assessment. More recent applications of the data are documented in SAHFOS Ecological Status Reports and a bibliography of publications is available at www.sahfos.org. An Atlas of the distribution of CPR plankton was published in Marine Ecology Progress Series [9]. For products from the North Pacific survey see [5]. Equivalent information for the Southern Ocean survey can be seen at: http://data.aad.gov.au/aadc/cpr and see also [10] and for bioregionalisation of the Southern Ocean for the Commission for the Conservation of Antarctic Marine Living Resources (CCAMLR) see [11]. Information on the NOAA/NMFS survey is available at: http://www.st.nmfs.noaa.gov/plankton/content/region_n atl.html and the new Australian survey at: http://imos.org.au/auscpr.html.

Research based on CPR survey data has led to well over 1000 scientific publications since 1931. Output is increasing as new ways of utilising the data are being discovered. In addition, samples held in storage ad infinitum make it possible for them to be reused as new scientific approaches and techniques become available. For example the CPR has proved to be a good sampler of small plastic particles and the samples are also being used for stable isotope analysis in a study of seabird distribution. A recent breakthrough in the extraction and characterisation of DNA from formalin preserved CPR samples has helped studies of plankton biodiversity and population biology. Finally, the samples hold great promise for biogeochemical analysis related to ocean acidification and the biological pump.

\section{THE NEED FOR GLOBALISATION}

A number of regional CPR programmes are now established or just starting throughout the world. It is time to build on the decadal experience of existing surveys and expand the CPR into all of the ocean basins and especially those that are climatically sensitive e.g. areas that are warming most rapidly. To achieve a coordinated global CPR programme we propose that existing and planned CPR surveys be integrated into a commonwealth of observing programmes linked to SAHFOS. The assistance of the merchant marine and ships of opportunity will be needed. The aim of this partnership will be to ensure common international standards of sampling, analysis, quality control, data processing and sample and data storage. This will enable broadly compatible data sets to be produced, without detracting from regional surveys, and facilitate inter-comparisons at a global scale. With standardised data formats, and a mandate of free data exchange, a CPR network would be well placed to interface with other traditional and new plankton sampling and analysing technologies as part of regional integrated marine observing programmes within the wider remit of the Global Ocean Observing System (GOOS), the Group on Earth Observations (GEO) and other global efforts to monitor biological activity such as the Global Tracking Network (GTN).

\subsection{Partnership with other SOOP monitoring programmes}

There are a number of existing and developing programmes using SOOP/VOS to monitor physico/chemical variables in the oceans, e.g. expendable bathythermographs (XBTs), thermosalinographs (TSG), $\mathrm{pCO}_{2}$ and acoustics (Fig. 5). Because they are instrumented methodologies they already have a more extensive global network than for the CPR. Automated sensors in flow through Ferry Box systems can also provide water samples for quantitative phytoplankton analyses that complement the sampling using the CPR. In developing a global programme, wherever possible, CPRs should be deployed on the same core routes and vessels used for these other measurements and on routes that pass close to OceanSITES (OCEAN Sustained Interdisciplinary Time series Environment observation System). There is a need to build a closer association between these different programmes so that they are not seen to be competing for ship-time by merchant ship operators. Sampling at the same time on the same route will provide benefits in terms of interpretation of change as well as possible sharing of logistics, costs and resources. 


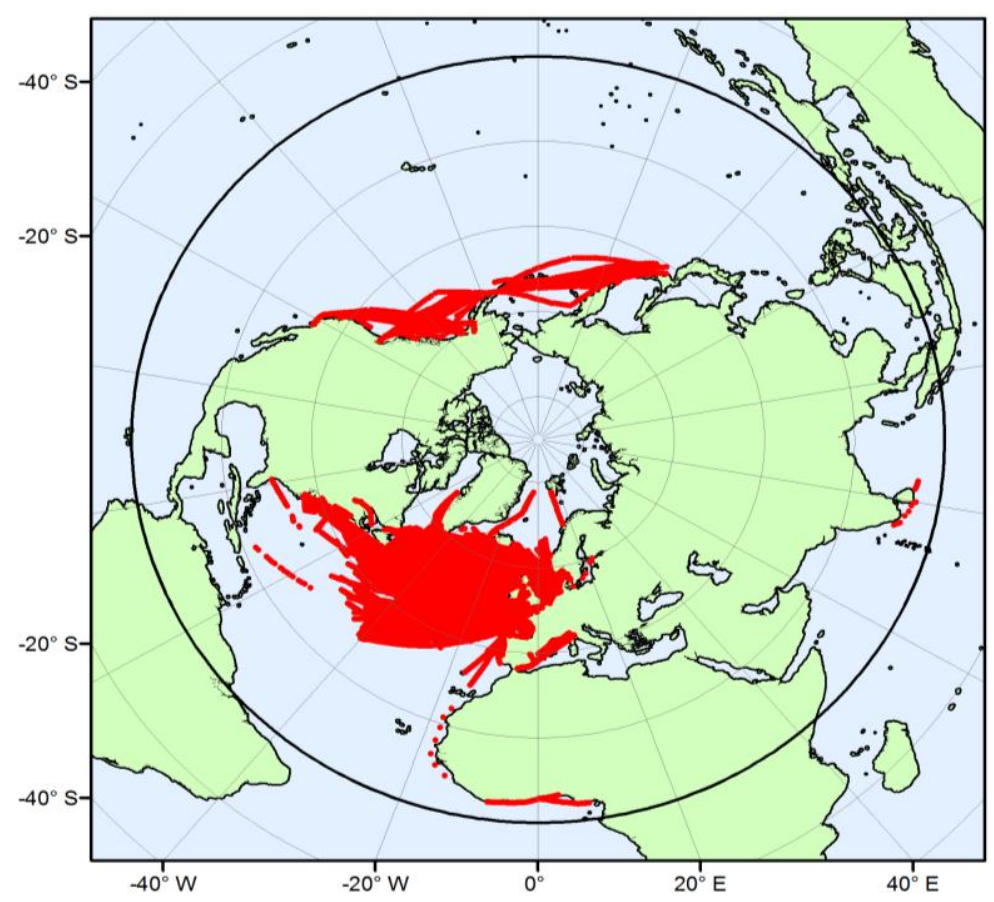

Figure 3. Map showing the positions of all analysed CPR samples in the Northern Hemisphere for the period 1931 to 2008 inclusive.

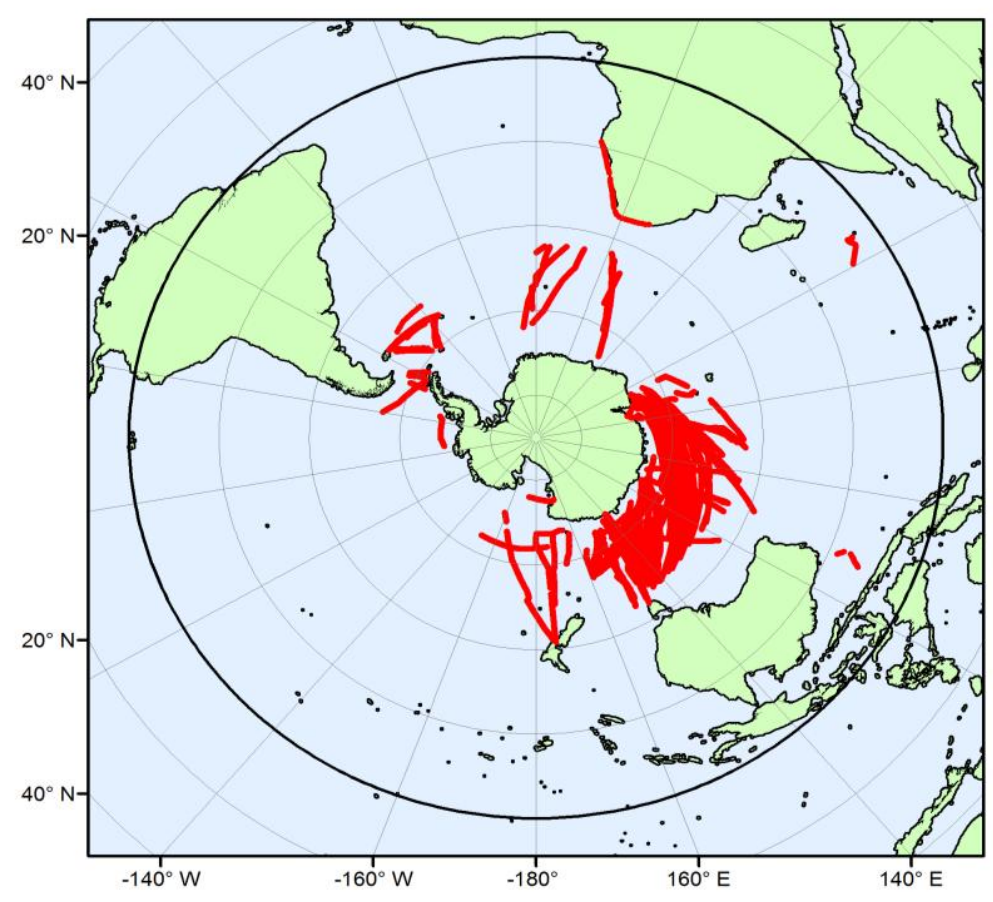

Figure 4. Map showing the positions of all analysed CPR samples in the Southern Hemisphere for the period 1991 to 2008 inclusive. 
There is considerable potential to deploy CPRs on untapped platforms, which should be used to further understand global, and basin-scale plankton dynamics and climate change.

\subsection{Integration with existing and planned regional marine observing systems}

The SAHFOS CPR survey has been an integral part of the UK National Marine Monitoring Programme, recently restructured as the United Kingdom Marine Monitoring and Assessment Strategy (UKMMAS), for many years. The routes in the western North Atlantic form part of the Canadian Atlantic Zone Monitoring Program [12] and [13], again linked to hydrographic and other measurements in Canadian waters and are used to produce annual assessments of the state of Canadian waters. In Australia CPR routes are interfaced with monthly plankton results from nine single point 'national reference stations', and will incorporate CPR data from SO-CPR operations south of Australia, all as part of a nation-wide collaborative programme, the Integrated Marine Observing System (IMOS).

The SCAR SO-CPR Survey was established in 1991 to map the spatio-temporal patterns of zooplankton, and to use the sensitivity of plankton to environmental change as early warning indicators of the health of the Southern Ocean [6]. The survey contributes to the CCAMLR Ecosystem Monitoring Program (C-EMP), a foundation component of the SCAR/SCOR Southern Ocean Observing System (SOOS) and contributes to the developing Southern Ocean Sentinel programme. Fourteen countries have participated to date to provide a near circum-Antarctic survey. Southern Ocean CPRs are towed from research and supply vessels (mostly in the austral summer) that simultaneously collect underway environmental data. There is thus already considerable experience in working closely with other diverse observing systems.

The best aspects of all these monitoring initiatives should be used as a model for the development of future regional programmes to establish a global 'commonwealth' of biological surveys. At a minimum these efforts should include remote sensing of Ocean Colour and the GTN for fish, marine mammals, turtles and other organisms. Integrating these different systems will provide a powerful mechanism to achieve synoptic comparisons between data on phytoplankton (remote sensing and CPR), zooplankton, fish larvae (CPR), and fish (GTN and stock assessment surveys). For successful development within a GOOS context, it is imperative that future programmes develop in partnership with parallel measurements of the physics and chemistry.

\subsection{European Union: Marine Strategy Framework Directive (MSFD)}

A new opportunity to establish a CPR programme in all European regional seas is possible under the new MSFD. Good environmental status targets for biological diversity, non-indigenous species, status of fish stocks and of the marine food web, eutrophication, benthic ecosystems and marine litter as well as indicators for each regional sea have to be developed by 2012 and a monitoring programme that includes both phyto and zooplankton has to be established by 2014 . Monitoring systems have to be compatible between each regional sea and with existing programmes. CPRs have already been successfully towed in the Northeast Atlantic, North, Norwegian, Barents, Baltic and Mediterranean seas, over decades in many areas. The natural variability of biological indicators has to be considered and this can only be achieved through long time series. Furthermore the standardisation of CPR methodologies allows comparability between different regional seas. Finally, CPR indicators are already in use by governments, the European Environment Agency and the Oslo-Paris Commission (OSPAR). The CPR could provide a cost-effective means of monitoring for the MSFD as it can simultaneously contribute many of the required indicators. CPR results provided some of the most convincing evidence for observed changes in marine ecosystems for the Intergovernmental Panel on Climate Change Fourth Assessment Report (IPCC AR4).

European funds may possibly be available to support partner CPR programmes elsewhere in the world, based on opportunities such as the Community Research and Development Information Service Seventh Framework Programme (CORDIS FP7). This programme includes a large set of International Co-operation Partner Countries

(ICPCs) ftp://ftp.cordis.europa.eu/pub/fp7/docs/icpc-list.pdf.

Additional links between ongoing CPR surveys and research institutions in non-European countries, particularly in the Southern Hemisphere, may be possible through bilateral or multilateral cooperation programmes such as the recently established agreement involving UK Research Councils and the Fundação de Amparo à Pesquisa do Estado de São Paulo (FAPESP) in Brazil.

\subsection{Linkages to GOOS, GEO, SCAR, SCOR/IAPSO OceanScope, SIBER, OceanSITES}

The proposals outlined in this White Paper will be developed in close cooperation with other observational themes developed by the new joint working group 'OceanScope' of the Scientific Committee on Oceanic 

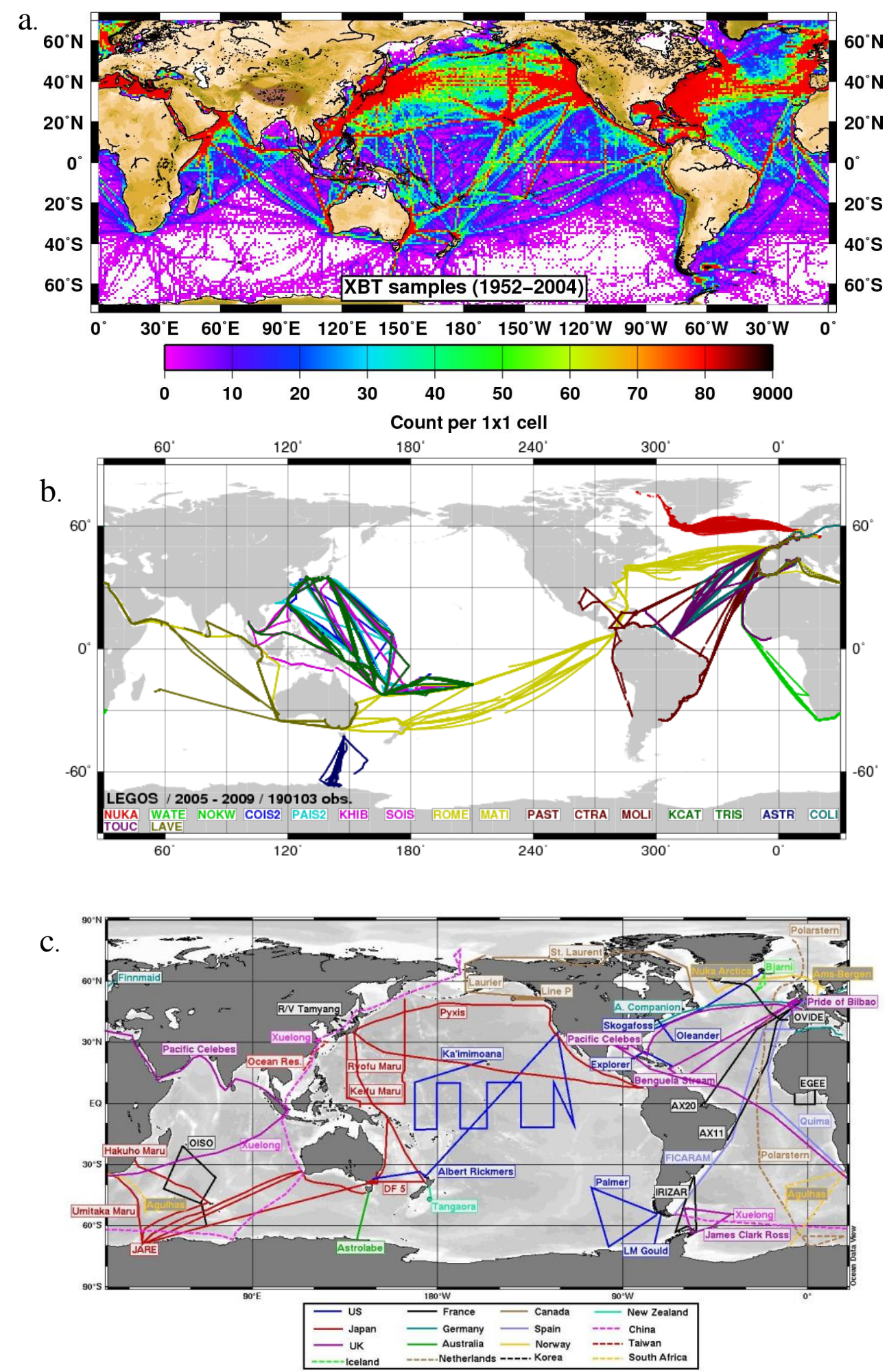

Figure 5. a: Dominant shipping routes and intensity of sampling by SOOP/VOS for XBTs (1952-2004), (data courtesy of NOAA/NODC).

b: Location of ship routes that have deployed thermosalinographs in real-time monitoring on SOOPs in the period January 2005 to September 2009 inclusive. Source: LEGOS/SSSOS http://www.legos.obs-

mip.fr/en/share/soa/cgi/getobs/v0.2/index.pl.cgi? contexte $=S S S \&$ donnees $=T S G \&$ suivi $=T P S$ REEL\&env $=$ NAVIRE\&men $=S P A T I A L$

c: Ongoing (and planned) routes used for surface measurement of $\mathrm{pCO}_{2}$ on SOOP. Source: IOCCP http://ioc3.unesco.org/ioccp/Underway/New_GlobalUWMap.html 
Research (SCOR) and the International Association for the Physical Sciences of the Oceans (IAPSO), ocean basin research proposals such as SIBER and initiatives within GOOS as well as linking to plankton assessments from remote sensed observations. The aim is to make best use of existing platforms to develop a coordinated whole.

\subsection{Data storage and data processing}

SAHFOS has invested sizeable resources into a new data input, storage and data extraction system that could be a model for application in a global database system. The SO-CPR uses a different system that includes data from measurements taken on the towing research vessel. To facilitate intercomparisons at ocean basin and regional scales between different $\mathrm{CPR}$ and other programmes there is a need to standardise data storage and processing procedures and to develop a global, distributed database system. Access to raw data for use by modellers is vital. A debate is needed on migrating to an international standard for taxonomic identifiers within each survey. Currently SAHFOS data are available from David Johns, Data Manager, djoh@sahfos.ac.uk. Data for the NOAA/NMFS survey are stored in the NMFS 'Copepod' database http://www.st.nmfs.noaa.gov/plankton/content/region_n atl.html and for the SO-CPR survey are held at the Australian Antarctic Data Centre http://data.aad.gov.au/aadc/cpr/ and at the SCAR Marine Biodiversity Information Network (SCARMarBIN) portal www.scarmarbin.be. The new programme in Australia forms part of the Integrated Marine Observing System (IMOS) with all data from hydrographic, chemical and other measurements incorporated into a central database. A link to the Open Access library PANGAEA (http://www.pangaea.de/) that aims to archive, publish and distribute georeferenced data from earth system research is already established. All CPR taxon presence data are made available to the Ocean Biogeographic Information System (OBIS, http://www.iobis.org), and from there to the Global Biodiversity Information Facility (GBIF, www.gbif.org). Data available on these sites, and on the SCAR Marine Biodiversity Information Network (SCAR-MarBIN), are maintained in synchrony mainly through the DiGIR protocol, using the Darwin Core as an exchange standard. This combination of transfer protocol and exchange standard has helped bring the biodiversity community together, as well as facilitating data exchange and integration on a large scale (see also CWP by Van den Berghe et al. [14]). Results from CPR surveys are made available within the context of general biodiversity, and can be analysed together with data from many other sources.

\subsection{Protocols and methods}

Since 1931 a CPR Manual has been regularly updated for all logistic, sampling, analysis and data processing protocols and a version of this manual has been produced more recently for the SO-CPR survey. A global version of this manual is needed that identifies differences between regional procedures, gives appropriate guidance on quality control and outlines standard training procedures. Taxonomic identification guides (with a section on molecular analysis) need to be maintained for different parts of the world. Small differences already exist between regional surveys that have crept in or were deliberately introduced due to local conditions e.g. species and stages analysed, numbers of nautical miles in a sample, on/off silk analysis.

\subsection{Instrumentation}

Additional measurements may be obtained by instrumenting CPRs and their tow ships to complement the plankton results. A range of instruments have been attached to CPRs in the past [3] and since 2007 small Vemco Minilog temperature recorders have been routinely deployed by SAHFOS on a number of routes in the North Atlantic. The time marked temperature records have a double use as they also provide a means of checking the hand-written log forms produced by the crew of towing ships for machine and cassettes used and date/time for entry and exit from the water. On one route in the northern North Sea salinity has also been measured from 2007. A new water sampling system has also been developed for attachment to a CPR. It is thus now possible to quantitatively measure the microbial and smaller components of the plankton along CPR routes.

\subsection{A special role for SAHFOS}

Within this global plan we suggest that SAHFOS, because of its past experience in establishing new and pilot plankton surveys and its taxonomic and logistical skill base, should play a central role as: a centre of advice, and expertise in survey design, quality control, databasing and coordination. It could also act as a global 'Centre of Excellence for Plankton Taxonomy and Ecology' and as a training centre to help establish new satellite laboratories and train their staff in analysis, QC and curation. To achieve these ends there is a need for:

1. New infrastructural and budget support for these roles in SAHFOS.

2. Staff at SAHFOS who are focussed on provision of advice, facilitating the development of new surveys plus work on plankton taxonomy and ecology. 
3. Support to enable SAHFOS to produce cost estimates for new surveys.

4. A revision of the SAHFOS guide to the development of new surveys and publication of the guide on the WWw.

5. A coordinating role for databasing and $\mathrm{QC}$ of data (see below).

6. Coordination of analysis and research on global results.

7. Production and maintenance of a global CPR manual for all protocols.

8. Improved facilities for molecular and biogeochemical analysis in cooperation with partner institutions.

9. Facilitating exchange of expertise and staff between different regional CPR programmes.

10. Training workshops on plankton taxonomy.

11. Global application of CPR indicators and ecological niche modelling.

\section{FINANCING CPR SURVEYS}

It is worth drawing attention to the history of how the North Atlantic survey has been funded as it provides insight into past mistakes and helps identify considerations that need to be addressed to achieve a global integrated CPR programme in the future. From its beginning in 1931 to 1989 what is now the SAHFOS North Atlantic survey was funded from research budgets by a succession of UK government agencies. In 1989 cuts had to be made and the survey was closed. Following an international outcry the survey was reopened the following week until a new charitable foundation (SAHFOS) was established to run the survey from April 1991. Since then more than 10 countries have supported and helped to expand the survey to cover a much larger area of the world's oceans. In 2007. core funding for SAHFOS derived from two UK agencies, the Natural Environment Research Council (NERC) and the Department for Environment, Food and Rural Affairs (Defra), comprising two thirds of the total funds and the remaining one third was funded by contracts requiring specific deliverables from more than a dozen research organisations in six countries, including the UK and the European Union. The SAHFOS Pacific survey, which started with four pilot tows in 1997, is developing along similar lines with agencies from the USA and Canada contributing to the funding package and a contribution in 2009 from the JSPS (Japan Society for the Promotion of Science, MEXT) to support sample analysis in Japan.

Funding by NOAA, USA supported an extension into the Northwest Atlantic between 1960 and 1979. After
1979 support from NOAA ceased and sampling stopped until 1991 when, under SAHFOS, routes were reopened with support from Canada and from the National Science Foundation (NSF) and NOAA, USA. The long gap in sampling from 1980 to 1991 in the Northwest Atlantic coincided unfortunately, with the collapse in the cod fishery and a major environmental change in the area. If the survey had been operational during this period it would have provided invaluable information to help understand the causes of the changes in cod stocks.

The temporary closure in the late 1980s had a major impact on the survey. All operations retreated to $20^{\circ}$ west in the East Atlantic, with a reduced sampling coverage and the analysis of samples ceased. In this period of uncertainty all the pre-war archived samples and samples prior to 1958 were thrown away. It now seems unbelievable that the true value of these well curated and preserved samples was not recognised. It is fortunate that the survey survived as a major ecological regime shift occurred in this area $\sim 1988$ that would not have been recognised if the closure had been complete. When the survey restarted after 1991 under a new funding regime it came close to bankruptcy on three occasions because of cash flow problems as a result of short (one year) multi-contract funding.

Surveys outside SAHFOS are serviced directly by Government agencies. The NOAA/NMFS CPR survey operates two short routes in the West Atlantic and is funded directly by NOAA with sample analysis contracted out to Poland. The Southern Ocean Survey is supported by the individual government and research institutes of the survey partners. A small amount of funding is provided by SCAR to support the Expert Group on CPR Research which helps promote the survey. The SO-CPR survey uses the supply vessels of $\mathrm{AAD}$ and is funded directly as part of the programme of AAD in the Southern Ocean and Antarctica, with contributions from other National Antarctic surveys that fund tows on their supply vessels. Aus-CPR is funded within the new Australian IMOS initiative until 2011. In New Zealand, NIWA has secured funding from the Ministry of Fisheries (Mfish) for five years from 2008.

The main problems of current funding approaches are their short term nature, lack of security and efficiency in supporting multiple contracts and minimal funding for research on the data and for archiving. The goal of a commonwealth of CPR programmes is to achieve a global perspective via a network of coordinated regional surveys, supported by long-term secure funding. To progress to a global programme a step-wise development is suggested. First, regional sea systems need to be put in place, building on existing operations and initially with multiple funding to the SAHFOS model, moving as soon as possible to regional support e.g. for Europe, potentially from the European Union to address the Marine Strategy Framework Directive. To 
achieve long-term global status co-ordinated regional funding, or preferably, a single global funding source linking regional programmes as per the model used for global meteorological observations, where funds are obtained directly from governments as contributions to the work of the World Meteorological Organisation (WMO), is required. A business plan needs to be developed that looks at different costing scenarios for global development. A full European/North Atlantic programme is estimated to cost $\sim 5$ million Euros/dollars per year. An additional ten million Euros/dollars would provide a basic survey throughout the rest of the world.

\section{OPERATIONAL PRODUCTS AND OUTREACH}

Other than for measures of sea surface temperature for meteorological services the SAHFOS CPR survey was probably the first truly operational oceanographic programme to be started in the world as it has provided products to governments, industry and the public from its inception in 1931. In developing a vision of how the spatially extensive areas of the global ocean should be sampled for plankton and its variability in the future and how such a programme should be integrated with other initiatives under a Global Ocean Observing Programme, it is essential that CPR surveys should continue to serve the needs and provide benefits to a wide user community. A primary focus should be the development of regional and global indicators, as not everything can be measured. CPR data, because of the large number of organisms identified and counted are particularly well suited to this type of application. Appropriate outreach and operational products need to be produced that are of value to governments, policy makers, researchers, modellers, remote sensors and the public at coastal, regional, oceanic and global scales.

\section{CONCLUDING COMMENTS}

A global plankton dataset is urgently needed to understand widespread evidence of changing marine ecosystems, as well as the impacts and feedbacks of plankton on climate. These plankton data should be complemented by additional biological, environmental and climatic indicators. Achieving consistency in sampling and analysis is essential for a coordinated global CPR programme that still accommodates local survey needs. A key step towards achieving this aim is to establish a global CPR network with a common operational base. SAHFOS, as the heart of CPR work to date, is the logical logistical location for such a base. An outstanding scientific legacy, coupled with the development of new sampling technologies for use with CPRs, and the fostering of a close working relationship with the shipping industry, makes the CPR an ideal tool for an expanded and comprehensive marine biological sampling programme.

\section{REFERENCES}

1. Taylor, A.H., Allen, J.I. and Clark, P.A., (2002). Extraction of a weak climatic signal by an ecosystem. Nature, 416 (6881), 629-632.

2. Richardson, A.J. et al., (2006). Using Continuous Plankton Recorder Data. Progress in Oceanography. 68, 27-74.

3. Reid, P.C., Colebrook, J.M., Matthews, J.B.L. and Aiken, J. (2003). The Continuous Plankton Recorder: concepts and history, from Plankton Indicator to undulating recorders. Progress in Oceanography. 58 (2-4), 117-173.

4. Jossi, J.W., John, A.W.G. and Sameoto, D. (2003). Continuous Plankton Recorder sampling off the east coast of North America: history and status. Progress in Oceanography, 58 (2-4), 313-325.

5. Batten, S.D. (2008). The North Pacific Continuous Plankton Recorder Survey. PICES Press. 16 (2), 1921.

6. Hosie, G.W., Fukuchi, M. and Kawaguchi, S. (2003). Development of the Southern Ocean Continuous Plankton Recorder Survey. Progress in Oceanography. 58 (2-4), 263-283.

7. Davies, C. et al. (2008). The Australian Continuous Plankton Recorder (AusCPR) survey: a plankton observing system in Australian waters. GLOBEC Newsletter. 14 (2), 17-18.

8. Brander, K.M., Dickson, R.R. and Edwards, M. (2003). Use of Continuous Plankton Recorder information in support of marine management: applications in fisheries, environmental protection, and in the study of ecosystem response to environmental change. Progress in Oceanography. 58 (2-4), 175-191.

9. Continuous Plankton Recorder Survey Team. (2004). Continuous Plankton Records: Plankton Atlas of the North Atlantic Ocean (1958-1999). II Biogeographical charts. Marine Ecology Progress Series Supplement. 11-75.

10. Leathwick, J.R., Elith, J., Francis, M.P., Hastie, T. and Taylor, P. (2006). Variation in demersal fish species richness in the oceans surrounding New Zealand: an analysis using boosted regression trees. Marine Ecology Progress Series. 321, 267-281.

11. Raymond, B. and Hosie, G. (2009). Network-based exploration and visualisation of ecological data. Ecological Modelling. 220 (5), 673-683. doi: 10.1016/j.ecolmodel.2008.12.011

12. Head, E.J.H. and Pepin, P. (2010). Spatial and interdecadal variability in plankton abundance and composition in the Northwest Atlantic (1958-2006). Journal of Plankton Research. 32 (12), 1633-1648. doi:10.1093/plankt/fbq090

13. Therriault, J.C. et al. (1998). Proposal for a northwest zonal monitoring program. Canadian Technical Report of Hydrography and Ocean Sciences. 194, pp 64. 
14. Vanden Berghe, E., Halpin, P., Lang da Silveira, F., Stocks, K. and Grassle, F., (2010). "Integrating Biological Data into Ocean Observing Systems: The Future Role of OBIS" in these proceedings (Vol. 2), doi:10.5270/OceanObs09.cwp.91 